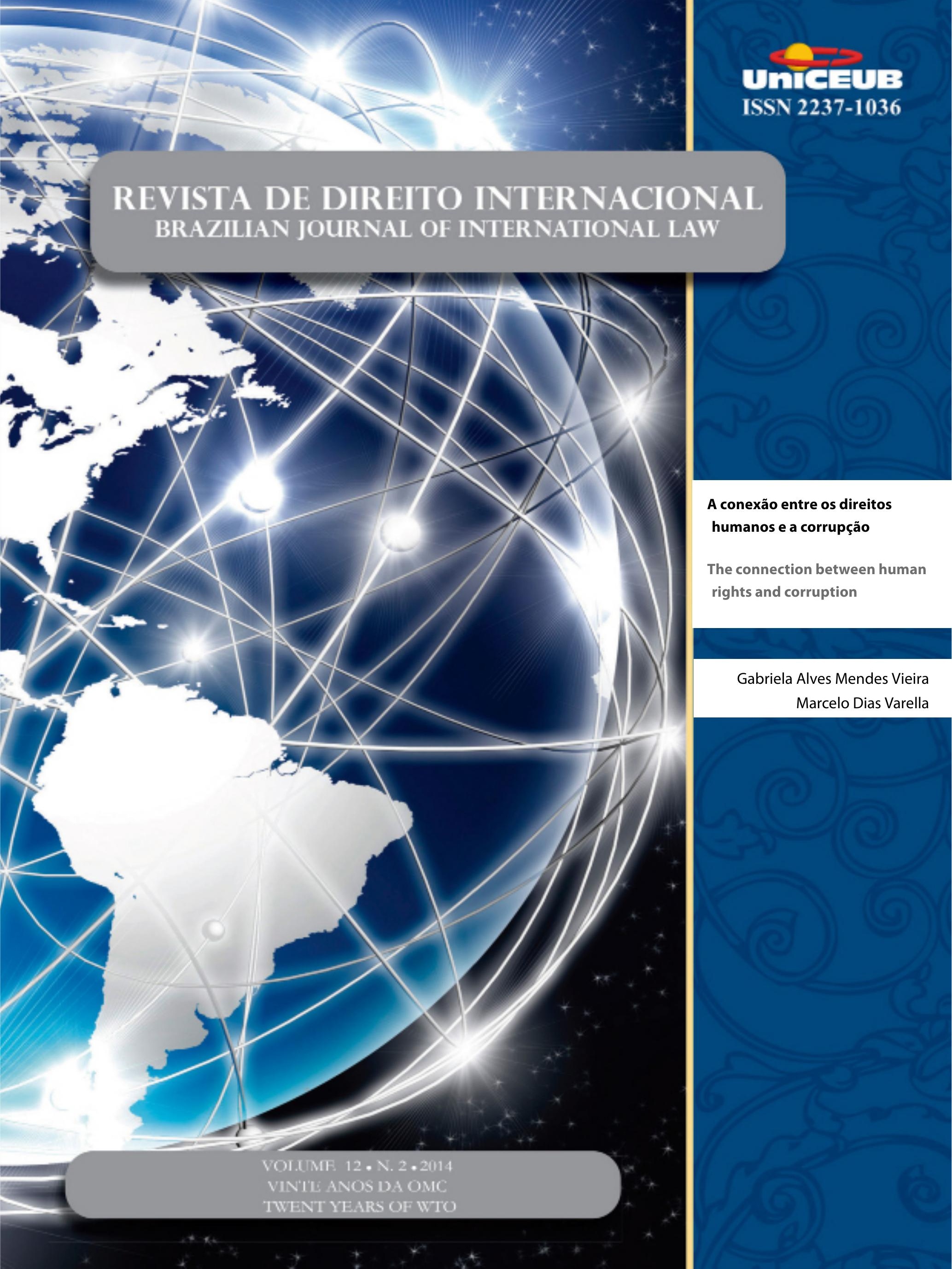


I. Crônicas

1. Crônicas da atualidade do Direito Internacional ......................................................16

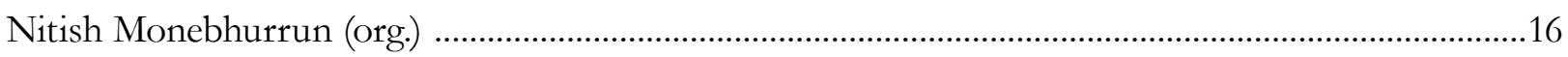

2.Decisões da Corte Internacional de Justiça e do Tribunal Internacional Sobre o Direito do Mar

Nitish Monebhurrun

José Eduardo Siqueira

3. Crônicas do direito internacional dos inVestimentos

Nitish Monebhurrun

\section{Os Vinte Anos dA OMC}

EXPORT CONTROLS AS INDUSTRIAL POLICY ON NATURAL RESOURCES: REGULATORY LIMITATIONS ON CHINA - RAW MATERIALS AND CHINA - RARE EARTHS CASES.

Gustavo Ferreira Ribeiro

O problema da espionagem econômica internacional: Seria a Organização Mundial do CoMÉRCIO O FORO ADEQUADO PARA SUA APRECIAÇÃO?

Humberto A.Vasconcelos Lima

Naiana Magrini Rodrigues Cunha

International Standards for Intellectual Property Rights Protection: a reflection on CLIMATE-FRIENDLY TECHNOLOGY TRANSFER.

Guihong Zhang

Jiani Jiang

Can Wang

Os vinte anos da OMC, suas conquistas e desafios: uma análise do Brasil e o Sistema de SoLUÇõES DE CONTROvÉRsias

Etiene M. Bosco Breviglieri

Luciano Meneguetti Pereira

A relação entre os tratados multilaterais ambientais e os acordos da OMC: é possível CONCILIAR O CONFLITO?

Fabio Costa Morosini,

Luisa Zuardi Niencheski 
Um desafio na Organização Mundial do Comércio: viabilidade de um aCordo plurilateral

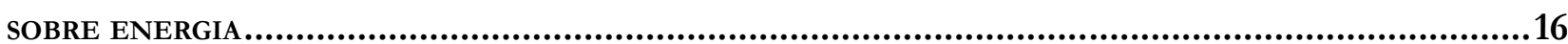

Matheus Linck Bassani

CoNTRATAÇõES PÚBLICAS NO ÂMBITO DA OMC: A POLÍTICA LEGISLATIVA BRASILEIRA À LUZ DO DIREITO AO DESENVOLVIMENTO

André Jansen do Nascimento

Governança global e a Organização Mundial do Comércio: desafios impostos pelo novo MANDATO DE DESENVOLVIMENTO

Letícia de Souza Daibert

Ana Luísa Soares Peres

Vinte Anos de Crise para a África? Poder, Assimetrias e a Abordagem Liberal da OMC.....239 Igor Abdalla Medina de Souza

Os MECANISMOS DE INDUÇÃo AO CUMPRIMENTO NO ÂMBITO DA OMC .258

Fernando Lopes Ferraz Elias

A promoção de accountability na Organização Mundial do Comércio: uma análise hori-

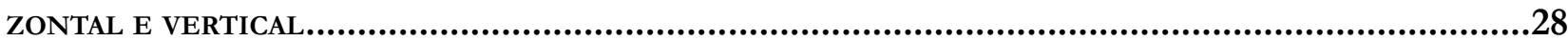

Celso Henrique Cadete de Figueiredo

LA OMC Y EL PROCESO DE GLOBALIZACION DE LA REGULACIÓN ALIMENTARIA .307

Maria Eugenia Marichal

O ACORDO GATS E SUA APLICAÇÃo AOS SERVIÇOS DO COMÉRCIO ELETRÔNICO .322

Gleisse Ribeiro Alves

A OMC E O REGIONALISMo do SÉCULO XXI: ESTRATÉGIA DE IMPOSIÇÃo DE MODELOS NORMATIVOs? .. 337 Camilla Capucio

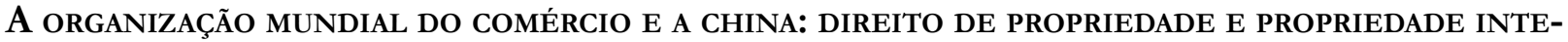
LECTUAL NO PAÍS .349

Dos CONTENCIOsos NA OMC COM ENFOQUE EM RESTRIÇÕES Às EXPORTAÇõES DA CHINA .363 Marco Antônio Alcântara Nascimento 
Alice Rocha da Silva

\section{Outros Temas}

Derechos Humanos en la REALIDAd ACTUAL: LA GLOBALIZACión Y El MUlTiCUlturalismo

David Falcão

IMUNIDADE DE JURISDIÇÃo do EsTAdo E REPARAÇÃo CIVIL PELA PRÁTICA DE TORTURA: O CASO ZaHRA

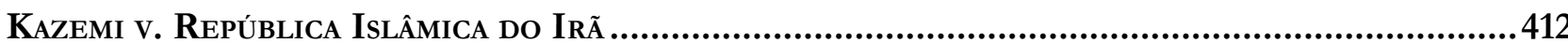

Patrícia Maria Lara Abreu

Rodrigo Otávio Bastos Silva Raposo

INTERREgIONAL ORgANIZATIONS (IROS) IN EUROPE: NEW SUBJECTS OF CONTEMPORARY INTERNATIONAL LAW?

Davorin Lapas

A conexão entre os direitos humanos e a CorrupÇão.

Gabriela Alves Mendes Vieira

Marcelo Dias Varella

GRUPO DE SOCIEDADES: INSTRUMENTO JURÍDICO DE ORGANIZAÇÃo DA EMPRESA PLURISSOCIETÁRIA.....495

Daniel Amin Ferraz 


\title{
A conexão entre os direitos humanos e a corrupção*
}

\section{The connection between human rights and corruption}

\author{
Gabriela Alves Mendes Vieira** \\ Marcelo Dias Varella***
}

\section{Resumo}

O combate à corrupção não pode ser considerado só como um fim em si mesmo, mas também como uma maneira de prevenir abusos de direitos humanos, de maneira que os institutos possam ser complementares. A proposta apresentada neste artigo se destina a demonstrar a integração dos direitos humanos nas agendas de combate a corrupção bem como a integração do combate à corrupção nas agendas de direitos humanos como uma chave para o sucesso mútuo. Primeiramente buscase esclarecer a necessidade da conceituação da corrupção, analisando como o tema é tratado nos principais instrumentos de combate à corrupção, bem como as suas causas e consequências multifacetadas que contribuem para o empobrecimento das economias nacionais ameaçando instituições democráticas, enfraquecendo o Estado de Direito e facilitando ameaças de direitos humanos. Como metodologia de análise, além de se analisar as principais agendas de combate à corrupção e as novas agendas que trazem a integração entre os direitos humanos e a corrupção, o trabalho explora como e quando um direito humano é violado e como práticas de atos de corrupção podem influenciar estas violações. Sendo assim, o presente artigo busca demonstrar, de maneira semelhante, a integração das normas e princípios de direitos humanos em programas de combate à corrupção e vice-versa.

Palavras-chave: Corrupção. Direitos Humanos. FCPA. Convenção da OCDE. UNCAC.

\section{Abstract}

The fight against corruption shall not be considered an end by its on means, but it is also a way to prevent human rights violations, in a sense that such themes should be complementaries. This article aims at demonstrating that adding human rights

* Recebido em: 30.10 .2014 Aceito em: 01.12.2014

${ }^{* *}$ Graduanda em Direito pelo Centro Universitário de Brasília - UniCEUB, gabrielaamv03@gmail.com.

*** Doutor em Direito e Livre-Docente. Professor do Programa de Mestrado e Doutorado do Centro Universitário de Brasília. Pesquisador do CNPq. O coautor figura como orientador do trabalho, desenvolvido pela primeira autora, marcelodvarella@gmail.com. concerns on corruption agenda, as well corruption on human rights agenda, are fundamental to mutual success. Initially, it is explained the concept of corruption, analyzing how this topic is approached in several anti-corruption instruments, and the main causes and consequences of this multifaceted phenomenon, which contributes to impoverish national economies, threatening democratic institutions, weakening state of law, and facilitating human rights violation. As a methodology, besides looking at the main anti-corruption agendas, mainly when related to human rights, this text also explores when a human right is violated and how corruption might influence such happening. Therefore, it is demonstrated the connection among norms and principles of human rights with fight against corruption programs.

Keywords: Corruption. Human Rights. FCPA. OEDC Convention. UNCA. 


\section{Introdução}

Apesar de quase intuitiva, a compreensão de que a corrupção afeta setores fundamentais do Estado e da sociedade, a conexão entre esse fenômeno e violações de Direitos Humanos ainda é pouca explorada pela doutrina especializada nos temas, e ainda se mostra incipiente nas principais Organizações Internacionais, apesar de relevante.

É indispensável, diante das interações sociais cada vez mais intensas e sistemas políticos cada vez mais complexos, as legislações e práticas de direitos humanos atribuam uma noção de participação fortalecendo as inciativas de combate à corrupção visando capacitar cidadãos e responsabilizar os governos. Problemas e suas respectivas soluções são construídos mutuamente em diversas áreas do conhecimento e essa não pode ser uma exceção.

Vista a tendência de sistemas corruptos para reproduzir os privilégios abusivos de elites, o empoderamento dos grupos vulneráveis deve ser um componente chave das estratégias de combate à corrupção, e aqui o princípio dos direitos humanos da não discriminação é um instrumento poderoso.

Destarte, cabe aprofundar os estudos nesse sentido, de modo a entender como que o combate à corrupção deve considerar os mecanismos de proteção dos Direitos Humanos; bem como as iniciativas de proteção de Direitos Humanos executarem seus trabalhos tendo em vista a corrupção também.

$\mathrm{Na}$ primeira parte do trabalho, apresentarse-á os tratados internacionais que versam sobre a corrupção, como uma forma de compreender os conceitos de corrupção trazidos por instrumentos internacionais, visualizar seus efeitos, tendo como foco as consequências na proteção de Direitos Humanos.

A segunda parte do trabalho se preocupa em consolidar a conexão entre ambos os institutos. Tanto em nível regional como internacional, a evolução dos mecanismos de responsabilização e de execução propostos pelos direitos humanos podem ser utilizados para fortalecer e aperfeiçoar as estratégias de combate à corrupção. A partir disso e de iniciativas de âmbito global, esse trabalho tem como fim estabelecer e consolidar a conexão entre a corrupção e suas formas de combate, com a violação de Direitos Humanos e suas perspectivas.

Ademais, preconiza-se ser um estudo crítico acerca da corrupção e a proteção de Direitos Humanos, em especial no âmbito internacional, identificando suas principais falhas e carências; coletando, por fim, propostas eminentes que ensejam a visão de concomitância entre esses assuntos.

\section{A difícil conceituação da corrupção e as suas implicações}

O questionamento sobre a definição do termo corrupção não traz respostas fáceis e nem muito claras. Essa dificuldade decorre em razão de ser um fenômeno sistêmico e intercultural; em outras palavras, a corrupção pode existir sobre qualquer forma de governo, em qualquer Estado e em qualquer momento. Perpassa pela doutrina uma dificuldade contínua na definição e conceituação do termo. ${ }^{1} \mathrm{Ou}$ seja, não há o que se falar em um consenso doutrinário sobre isso, inclusive se observada numa abordagem na História, que essa conceituação sempre sofreu variações ao longo do tempo. ${ }^{2}$

São inúmeras as definições do termo corrupção. Contudo, a mais aplicada é o abuso de poder confiado para ganhos privados, abrangendo tanto ganhos financeiros como não financeiros recebidos como resultado de atos de corrupção. Porém, a ampla definição do termo traz diferentes níveis e categorias de manifestação.

\subsection{Os conceitos trazidos pelos principais instrumentos legais de combate à corrupção}

A corrupção exige uma abordagem multidisciplinar, seja na ciência política, na economia ou na sociologia, cada uma delas traz suas definições sobre o fenômeno. A abordagem da ciência política apresenta a corrupção como um abuso do poder estatal resultante da ausência de controle ${ }^{4}$. Enquanto isso, os economistas identificam

FARRALES, M.J. What is corruption? a bistory of corruption studies and the great definitions debate, Carlifórnia, 2005. Disponível em: $<$ http://papers.ssrn.com/sol3/papers.cfm?abstract_id=1739962>. Acesso em: 02 set. 2014.

2 BARBOSA, Carlos Henrique N. A Cooperação internacional à luz da UNCAC: impactos no Brasil. 2014. f. Monografia (Graduação) - Faculdade de Direito - FD da Universidade de Brasília- UnB, Brasília, 2014.

3 BARR, Joshua V.; FINKE, Jorge; PINILLA, Edgar Michael. A legal perspective on the use of models in the fight against Corruption, Carolina do Sul, 2012. Disponível em: <http://scholarcommons. sc.edu/scjilb/vol8/iss2/5>. Acesso em: 02 set. 2014.

4 JOHNSTON, Michael. The political consequences of corruption: a reassement. Ph.D., Nova York, 1986. Disponível em: < http://www. 
a corrupção quando um bem público é vendido para um ganho pessoal ou quando funcionários públicos utilizam o seu monopólio para explorar os rendimentos econômicos. Há ainda uma abordagem sociológica, que vê a corrupção como uma ausência da aceitação social das normas, que ocorre nos países de conflitos históricos e socioeconômicos, resultando em um conflito de valores entre diferentes grupos sociais. ${ }^{5}$ Cada um com seu entendimento particular passou a estudar suas causas, efeitos e métodos pretendidos pelo fenômeno.

Definir o conceito de corrupção não é tão fácil como reconhecer a sua ocorrência, ${ }^{6}$ sendo esse exercício importante para a formação das proibições e controles legais. Segundo a professora Laura Underkuff, as definições de combate à corrupção devem incluir dimensões morais e sociais, além de como o fenômeno é popularmente recebido; uma vez que, quando um governo deixa de responder às emoções populares, essa recusa pode alimentar forças de instabilidade social e política.

Ao procurar por definições adequadas de corrupção, é importante trazer uma diferença gramatical e destacar que o foco aqui recai sob o substantivo corrupção e não sob o adjetivo e advérbio corrupto e corruptamente. Ou seja, não se busca aqui atribuir adjetivos, utilizando o termo corrupto, mas sim, trazer uma abordagem científica com o estudo do termo e fenômeno corrupção. ${ }^{8}$

A corrupção pode se manifestar de várias maneiras. Uma das formas de corrupção que os tratados internacionais de combate à corrupção têm em comum é o suborno de funcionários públicos estrangeiros, uma das heranças do UN International Code of Conduct for Public Offcials ${ }^{9}$, que reforçou a ideia de lealdade dos

jstor.org/stable/421694>. Acesso em: 30 ago. 2014.

5 SPALDING, Andrew Brady. Corruption, corporations, and the New Human Right. Washington, 2012. Disponível em: <http://ssrn. com/abstract $=2232670>$ Acesso em: 31 ago. 2014.

6 GOULD, D. J. Administrative corruption Incidence, causes and Remedial Strategies. In: FARAZMAND, Ali. Hand Book of Comparative Development and Public Administration. Nova York: Taylor \& Francis e-Library, 2005. p. 872-886.

7 UNDERKUFF, Laura S. Defining Corruption. In: ROTBERG, Robert I. Corruption, global security and world order. Washington D.C: Brookings Institution Press, 2009. p. 27-46.

8 SPALDING, Andrew Brady. Corruption, corporations, and the new Human Right. Washington, 2012. Disponível em: <http://ssrn. com/abstract $=2232670>$. Acesso em: 31 de ago. 2014.

9 UNITED NATIONS. A/RES/51/59: 82nd plenary meeting, 12 December 1996 Viena. 1997. Disponível em: <http:/ / www.un.org/documents/ga/res/51/a51r059.htm>. Acesso em: 31 ago. 2014. funcionários públicos. O foco no setor público reflete a definição tradicional de corrupção adotada pelo Banco Mundial como um ganho privado do funcionário público. ${ }^{10}$ Apesar da limitação ao setor público, algumas organizações ampliaram essa definição incluindo o setor privado nas suas abordagens, como é o caso do Banco Asiático de Desenvolvimento e da Transparência Internacional. Entretanto, deve-se prestar atenção nessa definição pautada no abuso do funcionário público para o ganho privado, uma vez que, o foco recai no abuso, e não necessariamente em quem obteve a vantagem indevida. ${ }^{11}$

O Banco Mundial aborda de maneira ampla o termo corrupção, de maneira que o termo engloba mais do que o suborno, abrangendo outras condutas ainda controvertidas e não pensadas geralmente como corrupção. Dessa maneira o conceito dado pelo Banco Mundial pode servir como uma definição ampla no combate à corrupção, mas não deve ser utilizado para uma proposta legal ${ }^{12}$.

A Lei de Práticas Corruptas no Exterior (Foreign Corrupt Practices Act FCPA $)^{13}$ proíbe formas específicas de corrupção como o suborno, de maneira que criminaliza apenas a oferta de suborno, mas não o recebimento. É importante verificar que uma das vítimas trazidas pela FCPA são os acionistas, e isso só é verificado em razão do suborno ter se tornado ilegal. Contudo, o suborno deixa vítimas antes mesmo da promulgação da FCPA. Existem dois tipos de vítimas: os cidadãos que vivem sob um regime corrupto, cujas regulações, segurança

10 Quando se fala em ganho privado é importante diferenciar do ganho pessoal. O ganho privado pode ser interpretado de uma maneira mais ampla do que o ganho pessoal. No ganho privado $\mathrm{o}$ ato corrupto pode beneficiar não só $\mathrm{o}$ funcionário que aceita $\mathrm{o}$ suborno, mas também quando o ganho vai para alguém da família, alguém da família, conhecidos ou ainda para a companhia que o funcionário público que aceitou o suborno trabalha. CLOOTS, Ann Sofie; RYNGAET, Cedric; WOUNTERS, Jan. The fight against corruption in international law. Bélgica, 2012. Disponível em: < https:// ghum.kuleuven.be/ggs/publications/working_papers/new_series/ wp91-100/wp94-jwouters-cryngaert-acloots.pdf> Acesso em: 31 ago. 2014.

11 CLOOTS, Ann Sofie; RYNGAET, Cedric; WOUNTERS, Jan. The Fight Against corruption in international law. Bélgica, 2012. Disponível em: <https://ghum.kuleuven.be/ggs/publications/ working_papers/new_series/wp91-100/wp94-jwouters-cryngaertacloots.pdf> Acesso em: 31 ago. 2014

12 SPALDING, Andrew Brady. Corruption, corporations, and the new human right. Washington, 2012. Disponível em: <http://ssrn. com/abstract $=2232670>$ Acesso em: 31 ago. 2014.

13 UNITED STATE. Department of Justice's. Foreign Corrupt Practices Act (FCPA). Washington, 1977. Disponível em:<http:// www.justice.gov/criminal/fraud/fcpa/>. Acesso em: 31 ago. 2014. 
e prosperidade se encontram comprometidas, e ainda há as empresas em conformidade com as normas antissuborno que perdem negócios para empresas que não aderem a essas normas. ${ }^{14}$

A Convenção sobre o Combate da Corrupção de Funcionários Públicos Estrangeiros em Transações Comerciais Internacionais da $\mathrm{OCDE}^{15}$ foi um dos primeiros instrumentos multilaterais de combate à corrupção, porém com alcance muito limitado a um tipo de corrupção e à realidade europeia. Mais tarde esse instrumento ampliou o seu alcance - inclusive geográfico - tanto em razão das pessoas atingidas quanto em razão dos tipos de corrupção abrangidos. ${ }^{16}$

A mais notável das definições encontrada nessa Convenção da OCDE, é que traz uma preocupação específica, não se restringindo preocupações com um fenômeno geral e suas manifestações. A primeira nota final da convenção traz o "suborno ativo" que é a oferta de suborno a uma autoridade estrangeira por um agente privado. Vale ressaltar que, nessa definição de corrupção, se estende a oferta ou pagamento de suborno por um agente privado.

A Convenção das Nações Unidas de Combate à Corrupção (UNCAC) ${ }^{18}$ o mais elaborado e detalhado dos instrumentos de combate à corrupção aqui trazidos, representou uma notável conquista aludindo responsabilidades globais para um problema global. O tratado enumerou atos específicos de corrupção, como por exemplo, o suborno, tráfico de influências e peculato, entretanto, em nenhum momento trouxe uma definição do termo em sentido amplo. Além de

14 CLOOTS, Ann Sofie; RYNGAET, Cedric; WOUNTERS, Jan. The fight against corruption in international law, Bélgica, 2012. Disponível em: <https://ghum.kuleuven.be/ggs/publications/ working_papers/new_series/wp91-100/wp94-jwouters-cryngaertacloots.pdf> Acesso em: 31 ago. 2014.

15 BRASIL. Decreto lei 3.678, de 30 de novembro de 2000. Promulga a Convenção sobre o combate da corrupção de funcionários públicos estrangeiros em transações comerciais internacionais, concluída em Paris, em 17 de dezembro de 1997. Brasília, 2000. Disponível em: <http://www.planalto.gov.br/ccivil_03/decreto/D3678.htm>. Acesso em: 31 ago. 2014

16 CLOOTS, Ann Sofie; RYNGAET, Cedric; WOUNTERS, Jan. The fight against corruption in international law, Bélgica, 2012. Disponível em: <https://ghum.kuleuven.be/ggs/publications/ working_papers/new_series/wp91-100/wp94-jwouters-cryngaertacloots.pdf> Acesso em: 31 ago. 2014.

17 SPALDING, Andrew Brady. Corruption, corporations, and the new human right. Washington, 2012. Disponível em: <http://ssrn. com/abstract $=2232670>$ Acesso em: 31 ago. 2014.

18 ORGANIZAÇÃO DAS NAÇÕES UNIDAS. Convenção das Nações Unidas Contra a Corrupção (UNCAC). Mérida: 2005. trazer medidas como a cooperação internacional e o retorno dos rendimentos da corrupção, as suas sanções se estendem a qualquer um que tenha concorrido para cometer delitos de corrupção. ${ }^{19}$

A UNCAC abrange não só a corrupção praticada por funcionários públicos estrangeiros, mas também funcionários públicos nacionais e funcionários de organizações internacionais públicas, e ainda, àqueles empregados de órgãos públicos, empresas públicas ou entidades que prestem serviço público. A mera promessa, oferta ou pedido de suborno já é suficiente para se enquadrar nos termos da convenção. ${ }^{20}$

\subsection{Instrumentos legais de combate à corrupção}

A Lei de Práticas Corruptas no Exterior (Foreing Corrupt Practices Act - FCPA) foi promulgada pelo Congresso Norte Americano em 1977 como uma resposta às inúmeras revelações de corrupção, envolvendo funcionários públicos estrangeiros e empresas norte-americanas. ${ }^{21}$ A FCPA acabou figurando como base para outras convenções, pois, além do amplo alcance das suas disposições jurisdicionais, serviu como referência para posteriores esforços internacionais no combate à corrupção de funcionários públicos estrangeiros. $^{22}$ A lei apresenta dois grandes componentes: o compliance e as penalidades civis e criminais, sendo que o compliance estabeleceu normas de manutenção de registros, e o segundo componente tornou certas práticas do comércio internacional ilegais. ${ }^{23}$

19 HECHLER, H. et. al. Can UNCAC address grand corruption? A political economy analysis of the UN Convention against corruption and its implementation in three countries. Berga, 2011. Disponível em: <http://www.u4.no/publications/can-uncac-address-grandcorruption/>. Acesso em: 31 ago. 2014.

20 CLOOTS, Ann Sofie; RYNGAET, Cedric; WOUNTERS, Jan. The fight against corruption in international law, Bélgica, 2012. Disponível em: < https://ghum.kuleuven.be/ggs/publications/ working_papers/new_series/wp91-100/wp94-jwouters-cryngaertacloots.pdf $>$ Acesso em: 31 ago. 2014.

21 UNITED STATE. Department of Justice and Enforcement Division of the U.S. Securities and Exchange Commission. A resource guide to the U.S. Foreing Corrupt Practices Act. Washington. 2012. Disponível em: <http://www.justice.gov/criminal/fraud/fcpa/ guide.pdf> Acesso em: 31 ago. 2014.

22 CLOOTS, Ann Sofie; RYNGAET, Cedric; WOUNTERS, Jan. The fight against corruption in international law, Bélgica, 2012. Disponível em: <https://ghum.kuleuven.be/ggs/publications/ working_papers/new_series/wp91-100/wp94-jwouters-cryngaertacloots.pdf $>$ Acesso em: 31 ago. 2014.

23 SNIDER, Thomas R; KIDANE, Won. Combating corruption 
Essa lei contém tanto medidas de antissuborno como medidas de contabilidade. As medidas antissuborno proíbem nacionais norte-americanos, empresas norteamericanas (questões internas ${ }^{24}$ ) e funcionários públicos estrangeiros de empresas que, listadas na bolsa de valores nos Estados Unidos, ou ainda, àquelas que são obrigadas a apresentar relatórios à Comissão de Valores Mobiliários (Securities and Exchange Commission - SEC), e certas pessoas e empresas que atuam temporariamente em território norte-americano para fazer pagamentos corruptos a funcionários públicos estrangeiros a fim de obter ou conservar negócios. ${ }^{25}$

Alguns autores defendem que há uma variação do princípio da territorialidade, permitindo uma interpretação bastante ampla do princípio da nacionalidade. $O$ que proporciona às agências de execução dos Estados Unidos (Departamento de Justiça e o SEC) processe uma pessoa estrangeira por crime de corrupção, cujos atos de suborno possam ter tido apenas uma tênue ligação com os Estados-Unidos, como por exemplo, quando um pagamento é enviado a contas bancárias nesse país. ${ }^{26}$

O Caso Siemens AG demonstra essa variação do princípio da territorialidade, sendo o caso sobre uma empresa alemã. A empresa foi processada por violações a FCPA, concordando com o pagamento de \$450 milhões pelas acusações criminais investigadas pelo Departamento de Justiça (DOJ) e $\$ 350$ milhões pelas acusações civis investigadas pela Comissão de Valores Mobiliários (SEC). O envolvimento do Departamento de Justiça norte-americano e o SEC decorrem do fato de a Siemens ser uma registrante no SEC, sendo, portanto, uma questão que cabe aos EUA. A empresa tinha ações listadas na bolsa de valores da New York

through international law in Africa: a comparative analysis. cornell intenational law, Seatle, v. 40, n. 691, p. 691-748, 2007.

24 Conforme o $\int 78 \mathrm{dd}-2(\mathrm{~h})(1)$, essas questões internas dizem respeito a qualquer indivíduo que é cidadão, nacional ou residente nos Estados Unidos. Ou ainda, a qualquer empresa, parceria, sociedade anônima, associação, organização sem personalidade jurídica que tenha a sua empresas principal sediada nos Estados Unidos, que seja organizada sob as leis americanas ou seu território, posses ou governo dos Estados Unidos.

25 UNITED STATE. Department of Justice's. Foreign Corrupt Practices Act (FCPA). Washington, 1977. Disponível em:<http:// www.justice.gov/criminal/fraud/fcpa/>. Acesso em: 31 ago. 2014.

26 CLOOTS, Ann Sofie; RYNGAET, Cedric; WOUNTERS, Jan. The fight against corruption in international law, Bélgica, 2012. Disponível em: <https://ghum.kuleuven.be/ggs/publications/ working_papers/new_series/wp91-100/wp94-jwouters-cryngaertacloots.pdf $>$ Acesso em: 31 ago. 2014.
Stock Exchange em março de 2001. Dessa forma o caso Siemens AG representou uma culminação de esforços por parte de autoridades de diversos países. ${ }^{27}$

As disposições que prescrevem as normas de manutenção dos registros se aplicam somente aos emitentes e exige que esta seja dada de forma detalhada, refletindo de maneira precisa e adequada as transações e alienações do emitente. A falha em cumprir com as normas de manutenção dos registros resulta em penalidades civis e criminais. ${ }^{28}$

A responsabilidade da execução da FCPA cabe à Comissão de Valores Mobiliários (SEC) e ao Departamento de Justiça (DOJ). O DOJ é responsável pela execução dos dispositivos criminais da FCPA e pela execução civil das violações antissuborno, desde de que respeitada as questões internas e empresas estrangeiras e nacionais, enquanto o SEC é responsável pela execução civil tanto das disposições antissuborno como das disposições de contabilidade, desde de que respeitado os emitentes de títulos. ${ }^{29}$

A partir dos impactos trazidos, principalmente pelo caso Watergate, a FCPA foi projetada para evitar práticas de corrupção, proteger os investidores e oferecer condições de igualdade para as empresas que estejam de acordo com as suas exigências, sendo um dos primeiros instrumentos jurídicos a abordar o suborno transnacional e restringir atividades empresariais corruptas. $^{30}$

A Convenção sobre o Combate da Corrupção de Funcionários Públicos Estrangeiros em Transações Comerciais Internacionais da OCDE (Convenção da OCDE) foi assinada no dia 17 de dezembro de 1997, tendo 38 países se tornado Estado Parte, inclusive o Brasil. A Convenção veio com o objetivo de assegurar uma equivalência funcional no suborno de funcionários

27 DARroughM, Masako N. The FCPA and the OCDE Convention: some lessons from U.S. experience. Nova York, 2010. Disponível em: <http://www.jstor.org/stable/40605340>. Acesso em: 02 set. 2014.

28 SNIDER, Thomas R; KIDANE, Won. Combating corruption through international law in Africa: a comparative analysis. cornell intenational law, Seatle, v. 40, n. 691, p. 691-748, 2007.

29 DARrougHM, Masako N. The FCPA and the OCDE Convention: some lessons from U.S. experience. Nova York, 2010. Disponível em: <http://www.jstor.org/stable/40605340>. Acesso em 02 set. 2014.

30 BARBOSA, Carlos Henrique N. A Cooperação Internacional à Luz da UNCAC: impactos no Brasil. 2014. Monografia (Graduação) - Faculdade de Direito - FD da Universidade de Brasília- UnB, Brasília, 2014. 
públicos estrangeiros sem exigir uniformidade ou mudanças nos princípios fundamentais no sistema legal de um Estado. ${ }^{31}$

A Convenção apresenta compacta semelhança com a FCPA, tendo seu escopo limitado a corrupção ativa, ou seja, incidindo sobre o doador do suborno. Exibindo rigorosos mecanismos de monitoramento, esse tratado tem seu processo dividido em duas etapas. A primeira etapa traz um sistema de autoavaliação com o objetivo de examinar em que medida o Estado Parte implementou medidas da convenção em sua legislação. A segunda fase avalia a implementação prática através do sistema de avaliação mútua. Esse processo de monitoramento foi implementado em 1991.

$\mathrm{O}$ artigo $8^{\circ}$ da Convenção da OCDE especifica os dispositivos de contabilidade que devem ser adotados pelos países signatários. Penalidades são propostas por omissões ou falsificações que digam respeito aos livros de registros das empresas e contas com a finalidade de subornar funcionários públicos estrangeiros ou esconder subornos. Além disso, o artigo também exige a divulgação de toda facilitação de pagamentos. Por conseguinte, a Convenção traz uma ótica das práticas de suborno, além de outros atos ilícitos praticados com o engajamento da iniciativa privada. ${ }^{33}$

AConvenção das Nações Unidas contra a Corrupção (UNCAC) foi o primeiro tratado global de combate à corrupção, servindo como marco nesse debate. No dia 01 de julho de 2012, 160 Estados, incluindo os Estados Unidos, Índia e China se tornaram parte da UNCAC, refletindo o amplo consenso internacional da convenção. Consenso compartilhado não só entre os Estados, mas também entre o setor privado internacional e a sociedade civil. ${ }^{34}$

31 CLOOTS, Ann Sofie; RYNGAET, Cedric; WOUNTERS, Jan. The fight against corruption in international law, Bélgica, 2012. Disponível em: <https://ghum.kuleuven.be/ggs/publications/ working_papers/new_series/wp91-100/wp94-jwouters-cryngaertacloots.pdf $>$ Acesso em: 31 ago. 2014.

32 CLOOTS, Ann Sofie; RYNGAET, Cedric; WOUNTERS, Jan. The fight against corruption in international law, Bélgica, 2012. Disponível em: <https://ghum.kuleuven.be/ggs/publications/ working_papers/new_series/wp91-100/wp94-jwouters-cryngaertacloots.pdf> Acesso em: 31 ago. 2014.

33 DARrougHM, Masako N. The FCPA and the OCDE Convention: some lessons from U.S. experience. Nova York, 2010. Disponível em: <http://www.jstor.org/stable/40605340>. Acesso em 02 set. 2014

34 CLOOTS, Ann Sofie; RYNGAET, Cedric; WOUNTERS,
Os três maiores focos da UNCAC são a prevenção, a criminalização e o seu cumprimento. ${ }^{35}$ Diferentemente de o que é estabelecido pela OCDE, que meramente recomenda aos Estados Partes que proíbam deduções fiscais de suborno, a UNCAC exige que o Estado Parte pró́ba tal prática. Contudo, as inovações da UNCAC não se restringem à criminalização de atos, mas também traz um enfoco na prevenção, assim como na cooperação internacional e na recuperação de ativos. $^{36}$

O Capítulo II da UNCAC expõe detalhadamente as medidas preventivas para práticas de corrupção tanto no setor público, quanto no setor privado, sendo estas predominantemente não obrigatórias, enfatizando o estabelecimento de políticas, capacitando organismos de controle independente e promovendo a conscientização pública. ${ }^{37}$ Entre outras medidas adotadas, estas incluem contratos transparentes, uma boa gestão financeira, um serviço público baseado no mérito, um efetivo acesso público à informação, auditoria e outras normas para empresas privadas, além de, um judiciário independente, um envolvimento ativo da sociedade civil e organizações não governamentais na prevenção e na luta contra a corrupção e medidas para prevenir a lavagem de dinheiro. ${ }^{38}$

Ademais, a UNCAC propõe que todos os Estados Partes criminalizem o suborno, o peculato de bens públicos e ainda, a obstrução da justiça. 39 A criminalização do suborno inclui tanto a

Jan. The Fight Against Corruption in International Law, Bélgica, 2012. Disponível em: <https://ghum.kuleuven.be/ggs/publications/ working_papers/new_series/wp91-100/wp94-jwouters-cryngaertacloots.pdf> Acesso em: 31 ago. 2014.

35 SNIDER, Thomas R; KIDANE, Won. Combating corruption through international law in Africa: a comparative analysis. cornell intenational law, Seatle, v. 40, n. 691, p. 691-748, 2007.

36 CLOOTS, Ann Sofie; RYNGAET, Cedric; WOUNTERS, Jan. The fight against corruption in international law, Bélgica, 2012. Disponível em: <https://ghum.kuleuven.be/ggs/publications/ working_papers/new_series/wp91-100/wp94-jwouters-cryngaertacloots.pdf $>$ Acesso em: 31 ago. 2014.

37 SNIDER, Thomas R; KIDANE, Won. Combating corruption through international law in Africa: a comparative analysis. Cornell Intenational Law, Seatle, v. 40, n. 691, p. 691-748, 2007.

38 HECHLER, H. et. al. Can UNCAC address grand corruption? A political economy analysis of the UN Convention against Corruption and its implementation in three countries. Berga, 2011. Disponível em: <http://www.u4.no/publications/can-uncac-address-grandcorruption/>. Acesso em: 31 ago. 2014.

39 HECHLER, H. et. al. Can UNCAC address grand corruption? A political economy analysis of the UN Convention against Corruption 
aceitação quanto o oferecimento, além de favores, apropriações indébitas e desvios. ${ }^{40}$ Alguns atos como o enriquecimento ilícito, o peculato de bens no setor privado, tráfico de influências, o abuso de função, a lavagem de dinheiro e a ocultação são atos incentivados a serem criminalizados e não exigidos ao Estado Parte.

As sanções se estendem àqueles que participam em tentativas de cometer crimes de corrupção. Medidas relacionadas ao cumprimento e processamento incluem proteção aos denunciantes, testemunhas, peritos e vítimas nos casos de corrupção, assim como o congelamento de bens e a compensação das vítimas. ${ }^{41}$

O Capítulo IV, da UNCAC traz a cooperação internacional como uma medida obrigatória em matéria criminal, podendo ser considerada em matéria civil ou administrativa, e no que tange a cooperação com instituições privadas, como os bancos, esta é somente encorajada. A exigência de que um Estado Parte coopere em matéria criminal é uma exigência necessária, mas uma condição insuficiente para uma efetiva recuperação de ativos, uma vez que muitas vezes, em casos envolvendo bancos e outras entidades, é necessário desencadear um processo para identificar o potencial das transações corruptas e notificar as autoridades oficias de tais transações. ${ }^{42}$

A recuperação de ativos veio como um "princípio fundamental" da UNCAC, uma das suas principais inovações e também das razões pelas quais muitos países desenvolvidos ratificaram a convenção. As medidas da UNCAC estabelecem uma estrutura para que os países adaptem a sua legislação civil e criminal para facilitar a identificação, localização e embargo preventivo, e o retorno de bens obtidos por meio de práticas corruptas. Essa exigência do Estado em

and its implementation in three countries. Berga, 2011. Disponível em: <http://www.u4.no/publications/can-uncac-address-grandcorruption/>. Acesso em: 31 ago. 2014.

40 SNIDER, Thomas R; KIDANE, Won. Combating corruption through international law in Africa: a comparative analysis. cornell intenational law, Seatle, v. 40, n. 691, p. 691-748, 2007.

41 HECHLER, H. et. al. Can UNCAC address grand corruption? A political economy analysis of the UN Convention against Corruption and its implementation in three countries. Berga, 2011. Disponível em: <http://www.u4.no/publications/can-uncac-address-grandcorruption/>. Acesso em: 31 ago. 2014.

42 CLOOTS, Ann Sofie; RYNGAET, Cedric; WOUNTERS, Jan. The fight against corruption in international law, Bélgica, 2012. Disponível em: < https://ghum.kuleuven.be/ggs/publications/ working_papers/new_series/wp91-100/wp94-jwouters-cryngaertacloots.pdf $>$ Acesso em: 31 ago. 2014. recuperar os bens é possível por meio da sua capacidade de provar a titularidade sobre o bem. ${ }^{43}$

Por fim, alguns dos mecanismos estabelecidos pela UNCAC, que determinam a aplicação da Convenção, é a avaliação por outros Estados Partes, sendo ainda feitas recomendações para melhorar a aplicação da Convenção. ${ }^{44}$ Ademais, é estabelecido a Conferência dos Estados Partes para monitorar a implementação da Convenção. ${ }^{45}$

\subsection{Quadros internacionais e outros instrumentos que relatam a corrupção e os direitos humanos}

O reconhecimento dos danos ocasionados pela corrupção pelos líderes de vários setores da sociedade contribuiu para que a corrupção passasse a ser um tema amplamente discutido na política internacional. $\mathrm{O}$ aumento de uma economia globalizada viveu e vive os danos que a corrupção traz ao desenvolvimento econômico. ${ }^{46}$

Uma análise da Declaração Universal dos Direitos Humanos $^{47}$, promulgada há mais de 60 anos, já lançava luz desse problema havendo uma divisão de opiniões: de uma lado os Estados Unidos e o Leste Europeu que abordavam os direitos humanos em termos políticos, como o direito à liberdade de expressão, e, de outro lado, estava a União Soviética e os países em desenvolvimento que abordavam os direitos humanos como uma capacidade governamental de garantir padrões mínimos de educação e bem-estar. ${ }^{48}$

43 HECHLER, H. et. al. Can UNCAC address grand corruption? A political economy analysis of the UN Convention against corruption and its implementation in three countries. Berga, 2011. Disponível em: <http://www.u4.no/publications/can-uncac-address-grandcorruption/>. Acesso em: 31 ago. 2014.

44 SNIDER, Thomas R; KIDANE, Won. Combating corruption through international law in Africa: a comparative analysis. Cornell Intenational Law, Seatle, v. 40, n. 691, p. 691-748, 2007.

45 CLOOTS, Ann Sofie; RYNGAET, Cedric; WOUNTERS, Jan. The fight against corruption in international law, Bélgica, 2012. Disponível em: < https://ghum.kuleuven.be/ggs/publications/ working_papers/new_series/wp91-100/wp94-jwouters-cryngaertacloots.pdf $>$ Acesso em: 31 ago. 2014.

46 BISHARA, N; HESS, D. Human rights and Corporation's Duty to Combat Corruption, Michigan, 2013. Disponível em: <http://ssrn. com/abstract $=2388395>$. Acesso em: 02 set. 2014.

47 ORGANIZAÇÃO DAS NAÇÕES UNIDAS. Declaração Universal dos Direitos Humanos, 10 dez, 1948.

48 BERENBEIM, Ronald. Linking Human Rights and to antiCorruption: how corruption connects with violations of human rights. Vital Speeches of the day, Nova York, v. 77, n. 2, p. 75-76, fev. 2011. 
O Pacto Global das Nações Unidas ${ }^{49}$ não é um instrumento de regulação, mas sim uma iniciativa voluntária que se baseia no accountability, na transparência e na divulgação de regulações e implementações de políticas corporativas. Essas estratégias estão alinhas aos 10 (dez) princípios universalmente aceitos nas áreas de direitos humanos, meio ambiente, trabalho e combate à corrupção. O Pacto Global das Nações Unidas traz uma mensagem implícita de que a corrupção viola direitos humanos de ambas as categorias ${ }^{50}$.

Entre os benefícios trazidos pela iniciativa voluntária, incluem-se: adotar uma estrutura política estabelecida e reconhecida mundialmente pelo desenvolvimento, implementação e divulgação de políticas e práticas ambientais, sociais e de governança; partilhar boas práticas emergentes para fazer avançar soluções e estratégias práticas para os desafios comuns; desenvolver soluções de sustentabilidade em parceria com uma série de partes interessadas, incluindo as agências da ONU, governos, sociedade civil, trabalho e outros interesses não comerciais; ligar as unidades de negócios e subsidiárias em toda a cadeia de valor com Redes Locais do Pacto Global em todo o mundo - muitas delas no desenvolvimento e mercados emergentes —; acesso a amplo conhecimento das Nações Unidas e experiências com as questões de sustentabilidade e de desenvolvimento; utilização de ferramentas do Pacto Global das Nações Unidas de gestão e recursos, bem como a oportunidade de participar de fluxos de trabalho especializados nos domínios ambientais, sociais e de governança. ${ }^{51}$

Apesar de integrar princípios entre as empresas, trazendo o estímulo a boas práticas, ao diálogo, à parceira com organizações da sociedade civil e promover a autorregulação das empresas, é um instrumento que carece de mecanismos de monitoramento e fiscalização independentes. Além disso, muitas empresas têm considerado o mecanismo vago e de difícil

49 UN GLOBAL COMPACT OFFICE. United Nations Global Compact, Corporate and Sustainability in the World Economy. 2014. Disponível em: <https://www.unglobalcompact.org/docs/ languages/portuguese/GC_Brochure_PT.pdf $>$ Acesso em: 02 set. 2014.

50 ORGANIZAÇÃO DAS NAÇÕES UNIDAS. United Nations Global Compact. 2014.

51 UNITED NATIONS GLOBAL COMPACT \& TRANSPARENCY INTERNATIONAL. Reporting Guidance on the $10^{\text {th }}$ principle against corruption. 2009. Disponivel em: <https://www. unglobalcompact.org/docs/issues_doc/Anti-Corruption/UNGC_ AntiCorruptionReporting.pdf > Acesso em: 02 set. 2014. implementação. Mesmo tendo sido bem-sucedido na conscientização das empresas, a iniciativa voluntária não conseguiu trazer a reconhecimento internacional das empresas em respeitar os direitos humanos. ${ }^{52}$

Em contrapartida, em 2011, foram aprovados, por unanimidade, no Conselho de Direitos Humanos das Nações Unidas, os Princípios Orientadores sobre Empresas e Direitos Humanos, que dão ênfase na responsabilidade internacional de respeitar os Direitos Humanos, invocando aos Estados que apliquem as leis que determinam que as empresas devem lidar com seus impactos sobre os direitos humanos. ${ }^{53}$

Os Princípios Orientadores têm como objetivo trazer uma distinção clara entre os papéis das empresas e dos governos em assegurar que ambos desempenhem suas funções. $O$ governo mantém a exclusiva responsabilidade pela proteção e cumprimento das obrigações de direitos humanos. Essa responsabilidade de respeitar os direitos humanos traz, direta e indiretamente, o dever das empresas de agir com a devida diligência para evitar infringir os direitos fundamentais, além de abordar os impactos nocivos com os quais estejam envolvidos. ${ }^{54}$

Entre as incitações que os Princípios Orientadores fazem para as empresas respeitarem os direitos humanos, as recomendações destacam que as empresas, em as suas atuações, devem evitar causar ou contribuir para impactos negativos nos direitos humanos e enfrentar esses impactos quando ocorrerem. Além disso, as empresas devem procurar mitigar os impactos negativos que estejam diretamente ligados às suas operações, produtos ou serviços por seus relacionamentos comerciais. Sendo assim, os Princípios Orientadores evidenciam que os impactos sobre os direitos humanos das empresas sejam comunicados ao público de forma suficientemente detalhado. ${ }^{55}$

52 SARFATY, Galit A. Human Rights meet securities regulations, Columbia. 2013. Disponível em: <http://ssrn.com/ abstract $=2390192>$. Acesso em: 02 set. 2014.

53 SARFATY, Galit A. Human Rights meet securities regulations, Columbia. 2013. Disponível em: <http://ssrn.com/ abstract $=2390192>$. Acesso em: 02 set. 2014.

54 BLITT, Robert C. Beyong Ruggie's guiding principles on busniss and Human Rights: charting an embracive approach to coporate Human Rights compliance. Texas International Law Journal, Texas, v. 48, n.158, p. 33- 62, mar. 2013.

55 BLITT, Robert C. Beyong Ruggie's guiding principles on busniss and Human Rights: charting an embracive approach to Coporate Human Rights Compliance. Texas International Law Journal, Texas, v. 48, n. 158, p. 33- 62, mar. 2013. 
Ainda que presentes as críticas, continua ganhando impulso a promoção de ações corporativas para combater a corrupção e proteger os direitos humanos. Sendo ainda inevitável falar do Pacto Global sem falar de direitos humanos. Entretanto, mesmo com o diagnóstico de que os impactos nocivos da corrupção afetam diretamente os direitos humanos reconhecidos pelo movimento de combate à corrupção, os institutos ainda caminham de maneira paralela. Demanda-se, pois, que caminhem juntos a fim de alcançar melhorias significativas, o que sugere para empresas um papel mais amplo no combate à corrupção. ${ }^{56}$

\section{A conexão entre a corrupção e os direitos humanos}

\subsection{Determinando quando um direito humano é violado}

Não necessariamente a prática de um ato de corrupção é determinante para a violação de um direito humano. É necessário estabelecer quando um direito humano é violado por práticas de ato de corrupção, determinando o seu nexo de causalidade. Desde que demonstrada que a ação (ou omissão) de um Estado não esteja em conformidade com as normas nacionais e internacionais de direitos humanos, sendo necessário determinar o alcance e o conteúdo da obrigação de direito humano e se deriva de uma norma interna, tratado de direito internacional, costume ou princípios gerais de direito.

Existem três níveis de obrigações de direitos humanos para os Estados: respeitar, proteger e cumprir. A obrigação de proteger traz para o Estado o dever de se abster de qualquer prática que prive a pessoa da fruição dos seus direitos ou capacidade de satisfazer esses direitos. Já o dever de proteção traz para o Estado o dever de evitar que danos irreparáveis ocorram sobre os membros da sociedade, de maneira que devem os Estados evitar violações de direitos humanos por parte de terceiros; evitar e eliminar incentivos para violar direitos de outrem; e fornecer acesso a recursos legais quando as violações ocorrerem. O não cumprimento dessas obrigações pode ser determinante para a

56 BISHARA, N; HESS, D. Human Rights and Corporation's Duty to Combat Corruption, Michigan, 2013. Disponível em: < http://ssrn. com/abstract $=2388395>$. Acesso em: 02 set. 2014.

57 INTERNATIONAL COUNCIL ON HUMAN RIGHTS POLICY. Corruption and Human Rights: making the connection, Suíça, 2009. Disponível em: <http://www.ichrp.org/files/ reports/40/131_web.pdf>. Acesso em: 12 set. 2014. responsabilização do Estado em casos de corrupção. Por exemplo, quando um Estado age de maneira negligente com empregadores que violam as leis trabalhistas ou ainda quando os fiscais do trabalho são sistematicamente subornados para ignorar esse tipo de comportamento. Além disso, a obrigação de cumprir traz para os Estados o dever de tomar medidas para que as pessoas sob a sua jurisdição tenham atendidas as suas necessidades básicas, principalmente quando estes não conseguem garantir tais necessidades por seus próprios esforços. ${ }^{58}$

Existem três relações causais entre a corrupção e as violações de direitos humanos, podendo a corrupção ser uma causa direta, indireta ou remota para as violações de direitos humanos. A corrupção pode ser diretamente ligada a uma violação de direito humano quando esse ato é deliberadamente utilizado para violar um direito, como por exemplo quando uma propina oferecida a um juiz afeta diretamente o seu dever de imparcialidade e independência, violando um julgamento justo. A corrupção pode indiretamente levar a uma violação de direitos humanos quando é uma condição necessária para a violação de um direito, sendo um fator essencial dentro de uma cadeia de atos praticados que, eventualmente, levará a violação de direitos humanos, como por exemplo, quando um funcionário público permite a importação ilegal de resíduos tóxicos em troca de suborno, permitindo que os resíduos fiquem perto de uma área residencial. Se o resíduo tóxico afetar as pessoas que ali vivem, haverá uma violação ao direito à vida ou à integridade. A corrupção poderá ainda violar os direitos humanos de maneira remota, de maneira que a corrupção é um dos elementos que leva a esta violação, como por exemplo, quando durante um processo eleitoral a corrupção desperta preocupações sobre a precisão do resultado formal, levando a agitações sociais e protestos, a repressão a estes protestos sociais poderá levar a graves violações de direitos humanos, não sendo a corrupção o único fator determinante..$^{59}$

58 INTERNATIONAL COUNCIL ON HUMAN RIGHTS POLICY. Corruption and Human Rights: making the connection, Suíça, 2009. Disponível em: <http://www.ichrp.org/files/ reports/40/131_web.pdf>. Acesso em: 12 set. 2014.

59 GEBEYE, Berihun Adugna. Corruption and Human Rights: exploring the relationship. Etiópia, 2012. Disponível em: <http://www. du.edu/korbel/hrhw/workingpapers/2012/70-gebeye-2012.pdf> Acesso em: 14 set. 2014. 


\section{A International Council on Human Rights Policy ${ }^{60}$} afirma que de várias maneiras a corrupção encoraja a discriminação, priva as pessoas vulneráveis de renda, e impede as pessoas de cumprir seus direitos políticos, sociais, civis, culturais e econômicos. Em 2005, no Kosovo, p Sr. Petrit Selimi entrou em um hospital em Pristina em uma condição não especificada. Segundo o Sr. Selimi, o guarda exigiu $€ 10$ a deixá-lo entrar no hospital. Posteriormente, o médico exigiu um suborno de cinco euros para vê-lo. O caso, pelo menos em teoria, envolve cinco infrações jurídicas separadas. A desigualdade ou deficiência preexistente no exercício efetivo dos direitos leva a uma situação em que o Sr. Selimi poderia ser extorquido por um suborno. Sr. Selimi pagou o suborno, o que resultou em seu tratamento médico preferencial. Seu tratamento preferencial implica necessariamente que outras pacientes receberam um nível menor de cuidados de qualidade do que o Sr. Selimi. A falha em detectar o delito de suborno representa, em si, a negligência potencial. Uma vez que a história foi ao ar na televisão, a falta de uma condenação por suborno provavelmente reflete, também, a corrupção (ou negligência) nos sistemas policiais e judiciais. ${ }^{61}$

Situações como essa permitem verificar que a corrupção constitui uma violação dos direitos humanos, enfatizando o impacto maléfico sobre os cidadãos mais vulneráveis ${ }^{62}$. Dessa maneira, o combate à corrupção pode ter grande relevância na promoção dos direitos humanos, garantindo a não discriminação e a participação social; levando, destarte, a capacitação e responsabilidade social. ${ }^{63}$

60 A International Council on Human Rights Policy (ICHRP) é uma organização não-governamental que foi concebida em 1994, composta por um pequeno grupo de defensores dos direitos humanos, estudiosos e gestores de políticas conduzidos por Philip Alston, Thomas Hammarberg e Margo Picken com a finalidade de enfrentar dilemas e desafios nas áreas de direitos humanos. Disponível em: <http://www.ichrp.org/en/history>. Acesso em 14 set. 2014.

61 MICHAEL, Bryane; HAJREDINI, Habit. Topics in anticorruption law: what does Kosovo teach us about using Human Rights Law to prosecute corruption offences? Estocolmo, 2010. Disponível em: < http://works.bepress.com/bryane_michael/52 >. Acesso em: 14 set. 2014.

62 UNDERKUFF, Laura S. Defining corruption. In: ROTBERG, Robert I. Corruption, global security and world order. Washington D.C: Brookings Institution Press, 2009. p. 27-46.

63 GEBEYE, Berihun Adugna. Corruption and Human Rights: exploring the relationship. Etiópia, 2012. Disponível em: < http://www. du.edu/korbel/hrhw/workingpapers/2012/70-gebeye-2012.pdf> Acesso em: 14 set. 2014.

\subsection{O impacto da corrupção sobre os direitos humanos}

O preâmbulo da UNCAC declara a preocupação dos Estados-partes com as ameaças trazidas pela corrupção que promovem instabilidade e insegurança nas sociedades, minando instituições de valores, a democracia e valores éticos, além de comprometer o desenvolvimento sustentável de um Estado de direito. Da mesma forma, o Conselho Europeu destacou fenômeno da corrupção como uma ameaça não só ao Estado de Direito e à democracia, mas também aos direitos humanos, trazendo impactos nocivos a um bom governo, à justiça, distorcendo as competições, dificultando o desenvolvimento da economia e colocando em perigo a estabilidade das instituições democráticas. ${ }^{64}$

Sendo um adversário social, político e econômico, a corrupção resulta direta e indiretamente em violações de direitos e liberdade fundamentais. $O$ fenômeno afeta a própria natureza da igualdade e da dignidade humana. A $11^{a}$ Conferência Internacional sobre Corrupção destacou a incompatibilidade do fenômeno da corrupção com ideais de humanidade trazidos pela Declaração Universal de Direitos Humanos. Além disso, a Convenção da União Africana sobre a Prevenção e o Combate à Corrupção trazem a ligação entre a corrupção e os direitos humanos afirmando expressamente que a corrupção representa uma ameaça aos direitos humanos. ${ }^{65}$

Nos países africanos, a corrupção está diretamente relacionada ao mau desempenho escolar. A população mais pobre depende do sistema de ensino público para educação. Entretanto, o suborno é uma das práticas de corrupção utilizado como uma condição prévia para que alguns estudantes sejam admitidos, prejudicando o sistema de ensino e violando direitos fundamentais como a educação e o direito à igualdade. Há ainda o suborno com a finalidade de obter certificados, professores que subornam funcionários públicos a fim de obter transferências de escolas localizadas em áreas de difícil acesso, regiões que em grande parte são atingidas pela pobreza e demandam professores qualificados. Esse é um dos exemplos que demonstram como uma pequena corrupção pode desencadear elevados custos a uma população, particularmente aos mais pobres. ${ }^{66}$

64 KOECHLIN, Lucy; CARMONA, Magdalena Sepúlveda. In: ROTBERG, Robert I. Corruption, global security and world order. Washington D.C.: Brookings Institution Press, 2009. p. 310-340.

65 GEBEYE, Berihun Adugna. Corruption and Human Rights: exploring the relationship. Etiópia, 2012. Disponível em: <http://www. du.edu/korbel/hrhw/workingpapers/2012/70-gebeye-2012.pdf> Acesso em: 14 set. 2014.

66 GATHII, James Thuo. Defining the relationship between Human 
Não se procura evidenciar os direitos humanos como o único e melhor instrumento de combate a corrupção disponível, mas sim demonstrar que a análise do quadro de direitos humanos produz impactos positivos em certas áreas que são chaves para reformas no combate a corrupção. Esse quadro amplia os sistemas de accountability, transparência e integridade que dão suporte as reformas de combate a corrupção. ${ }^{67}$ Quando países deixam de assegurar direitos como a liberdade de expressão, direito de reunião e associação, participação política em condições de igualdade, e ainda, quando alguns setores da sociedade são excluídos ou marginalizados, encontrase um ambiente propício para a corrupção e a dificuldade de responsabilização dos governos e empresas. ${ }^{68}$

Rights and corruption. Pensilvânia, 2013. Disponível em: <http://ssrn. com/abstract=1342649>. Acesso em 15 set. 2014.

67 KOECHLIN, Lucy; CARMONA, Magdalena Sepúlveda. In: ROTBERG, Robert I. Corruption, global security and world order. Washington D.C.: Brookings Institution Press, 2009. p. 310-340.

68 BRASIL. Ministério da Justiça. Guia para o uso do Sistema Interamericano de Direitos Humanos na proteção dos denunciantes de atos de corrupşão. Brasília, 2014. Disponível em: <http://www.justica.gov.br/ sua-protecao/lavagem-de-dinheiro/institucional-2/publicacoes/ arquivos /guia-para-uso-do-sidh-na-protecao-de-denunciantes-deatos-de-corrupcao.pdf>. Acesso em: 01 out. 2014.
Ainda permanecem tênues os litígios envolvendo violações de direitos humanos que conjuram elementos de combate à corrupção. A tabela abaixo elenca casos que apareceram frente ao Tribunal Europeu dos Direitos Humanos por violações a Convenção Europeia dos Direitos Humanos trazendo casos em que os direitos humanos foram postos a partir de elementos da corrupção. Nesses casos o Tribunal considera alguns elementos relacionados aos direitos humanos. Em primeiro lugar, defende-se o direito de compartilhar informações sobre práticas de corrupção, o que é protegido pelo direito à liberdade de expressão. ${ }^{69} \mathrm{Um}$ dos elementos chaves defendidos, inclusive pela UNCAC com a finalidade de atingir a "cultura política que incentiva, nutre e reforça a exposição e punição" da corrupção. ${ }^{70}$ Em segundo lugar, o Tribunal defende os direitos dos suspeitos envolvidos e condenados por crimes e práticas de corrupção.

69 MICHAEL, Bryane; HAJREDINI, Habit. Topics in anticorruption law: what does Kosovo teach us about using Human Rights Law to prosecute corruption offences? Estocolmo, 2010. Disponível em: < http://works.bepress.com/bryane_michael/52 >. Acesso em: 14 set. 2014 .

70 TERRACINO, Julio Bacio. Hard law connections between corruption and Human Rights. Genebra, 2010. Disponível em: < http://www. ichrp.org/files/papers/130/131_-_Julio_Bacio_Terracino_-_2007. pdf>. Acesso em: 18 set. 2014. 


\begin{tabular}{|c|c|c|}
\hline Casos & Elementos & Implicações da lei de corrupção \\
\hline \multicolumn{3}{|l|}{ Liberdade de expressão } \\
\hline Guja vs. Maldávia (1 4277/04) & & $\begin{array}{l}\text { A Corte considera o vazamento de docu- } \\
\text { mentos confidenciais de interesse público } \\
\text { para combater a corrupção. A liberdade } \\
\text { de expressão tem papel vital no combate à } \\
\text { corrupção. }\end{array}$ \\
\hline $\begin{array}{l}\text { Cumpana e Mazaré vs. Romênia } \\
(33348 / 96)\end{array}$ & $\begin{array}{l}\text { Cartunistas acusaram um político de } \\
\text { corrupção. A Corte reverteu a decisão } \\
\text { do governo. }\end{array}$ & $\begin{array}{l}\text { O papel da liberdade de expressão no } \\
\text { combate à corrupção suspende os direitos } \\
\text { individuais (acusações de calúnia forma } \\
\text { derrubadas). }\end{array}$ \\
\hline Stoll vs. Suíça (69698/01) & $\begin{array}{l}\text { O requerente alegou que a sua condena- } \\
\text { ção por publicar "deliberações oficiais } \\
\text { secretas" tinha sido contrária ao artigo } \\
10 \text { da Convenção. }\end{array}$ & $\begin{array}{l}\text { O direito à liberdade de expressão não é } \\
\text { absoluto. Jornalista deve seguir a ética pro- } \\
\text { fissional na liberação de informações para o } \\
\text { público. }\end{array}$ \\
\hline Sisojeva vs. Letónia $(60654 / 00)$ & $\begin{array}{l}\text { Requerente se recusou a ficar na Letó- } \\
\text { nia alegando retaliação por denunciar } \\
\text { corrupção na Letónia em um programa } \\
\text { de TV na Rússia. CEDH considerou o } \\
\text { apelante como sido deportado. }\end{array}$ & $\begin{array}{l}\text { A Corte — ao ouvir o caso — levou a sério } \\
\text { as alegações de que o governo viola os direi- } \\
\text { tos humanos para encobrir a corrupção. A } \\
\text { Corte certamente é contra as decisões ilegais } \\
\text { tomadas por causa da corrupção. }\end{array}$ \\
\hline \multicolumn{3}{|l|}{ Julgamento Justo } \\
\hline $\begin{array}{l}\text { Ramanauskas vs. Lituânia } \\
(74420 / 01)\end{array}$ & $\begin{array}{l}\text { Recorrente afirma que ele foi vítima } \\
\text { de armadilha para a corrupção e na } \\
\text { oportunidade se negou a examinar uma } \\
\text { testemunha-chave. }\end{array}$ & $\begin{array}{l}\text { As autoridades policiais devem seguir Es- } \\
\text { tado de Direito nos processos de combate } \\
\text { a corrupção. A Corte respeita os direitos } \\
\text { humanos dos suspeitos em casos de corrup- } \\
\text { ção. }\end{array}$ \\
\hline Kart vs. Turquia $(8917 / 05)$ & $\begin{array}{l}\text { Em um caso raro, um membro do Par- } \\
\text { lamento solicitou imunidade para que } \\
\text { pudesse se defender contra acusações } \\
\text { de corrupção. A Corte concluiu que } \\
\text { o governo se recusou a conceder a } \\
\text { imunidade. }\end{array}$ & $\begin{array}{l}\text { A noções comumente admitidas pelos indi- } \\
\text { víduos dizem que a imunidade parlamentar } \\
\text { impede o trabalho de combate à corrupção. } \\
\text { Caso dará nova perspectiva para os próxi- } \\
\text { mos anos. }\end{array}$ \\
\hline H.L.R. vs. França & $\begin{array}{l}\text { Recorrente pretende derrubar or- } \\
\text { dem de deportação para a Colômbia. } \\
\text { Reivindicações corrupção no sistema } \\
\text { judicial colombiano irão privá-lo de um } \\
\text { julgamento justo. }\end{array}$ & $\begin{array}{l}\text { Os países têm dever de não fornecer assis- } \\
\text { tência às cegas, mas considera a proteção } \\
\text { dos direitos humanos em casos julgados no } \\
\text { exterior. }\end{array}$ \\
\hline $\begin{array}{l}\text { Guerin vs. França } \\
(25201 / 94)\end{array}$ & $\begin{array}{l}\text { Oficial francês foi subornado. O ape- } \\
\text { lante foi privados do direito efetivo de } \\
\text { um recurso. A CEDH julgou a favor do } \\
\text { recorrente. }\end{array}$ & $\begin{array}{l}\text { Teve pouca relevância na teorização da lei } \\
\text { de combate a corrupção. }\end{array}$ \\
\hline Na. vs Reino Unido (25904/07) & $\begin{array}{l}\text { O Sr. Na - um nacional do Sri Lanka- } \\
\text { admitiu ter pago suborno para escapar } \\
\text { autoridades cingalesas. CEDH conside- } \\
\text { ra risco real devolver o nacional ao Sri } \\
\text { Lanka. }\end{array}$ & $\begin{array}{l}\text { No caso notável, a Corte condena implici- } \\
\text { tamente pagamento de propina em um país } \\
\text { altamente disfuncional. A questão da extra- } \\
\text { dição relativamente sem importância. }\end{array}$ \\
\hline $\begin{array}{l}\text { Gorgievski vs. Macedônia } \\
(18002 / 02)\end{array}$ & $\begin{array}{l}\text { O apelante alega ter caído em uma } \\
\text { armadilha para pagar suborno. }\end{array}$ & $\begin{array}{l}\text { A Corte se abstém deliberadamente de fazer } \\
\text { julgamentos sobre os direitos humanos } \\
\text { relacionados a julgamentos doméstico na } \\
\text { Macedônia com base na lei de combate à } \\
\text { corrupção da Macedônia. }\end{array}$ \\
\hline
\end{tabular}




\begin{tabular}{|c|c|c|}
\hline Miliniene vs. Lituânia & $\begin{array}{l}\text { A apelante (juíza) alega que foi presa } \\
\text { pela polícia }\end{array}$ & $\begin{array}{l}\text { CEDH falha (novamente) para manifestar- } \\
\text {-se sobre direitos humanos aspectos } \\
\text { relacionados de quadro legal de combate à } \\
\text { corrupção. }\end{array}$ \\
\hline Abramyan vs. Rússia & $\begin{array}{l}\text { O caso do recorrente foi reclassificado } \\
\text { como corrupção por fraude - causando } \\
\text { um novo julgamento. Ele e o advogado } \\
\text { não apresentaram ao julgamento, sendo } \\
\text { reclassificado (onde ele foi considerado } \\
\text { culpado). A Corte julgou a favor do } \\
\text { recorrente. }\end{array}$ & Caso pouco relevante. \\
\hline $\begin{array}{l}\text { Vilvarajah e outros vs. Reino } \\
\text { Unido }\end{array}$ & $\begin{array}{l}\text { Basicamente o mesmo caso do Sr. Na } \\
\text { vs. Reino Unido (mas cerca de uma dé- } \\
\text { cada antes). A Corte não encontrou ne- } \\
\text { nhum risco de maus-tratos. Recorrentes } \\
\text { também admitiram a pagar suborno. }\end{array}$ & $\begin{array}{l}\text { Tal como acontece com } \mathrm{Na} \text {, tribunal parece } \\
\text { negligenciar elementos de corrupção do } \\
\text { caso. }\end{array}$ \\
\hline \multicolumn{3}{|l|}{ Tratamento Desumano } \\
\hline $\begin{array}{l}\text { Victor Savtchi vs. Maldávia } \\
(81 / 04)\end{array}$ & $\begin{array}{l}\text { Membro da polícia econômica foi su- } \\
\text { bornado. Ele é agredido e afirma que as } \\
\text { provas contra ele são injustas (escutas } \\
\text { telefônicas etc.). CEDH reconhece em } \\
\text { seu favor as agressões, mas não consi- } \\
\text { dera os métodos utilizados pelo como } \\
\text { violadores de direitos humanos. }\end{array}$ & $\begin{array}{l}\text { CEDH - neste caso, como em outros - } \\
\text { concentra-se mais em direitos humanos e } \\
\text { menos sobre a adesão ao Estado de direito. }\end{array}$ \\
\hline Dorokhov vs. Rússia (66802/01) & $\begin{array}{l}\text { O ex-procurador acusado por abusos } \\
\text { poder e levar subornos. Reivindicações } \\
\text { segurando condições horríveis. CEDH } \\
\text { concorda. }\end{array}$ & $\begin{array}{l}\text { Outra "espírito da lei" caso - tribunal tende } \\
\text { a olhar para os resultados, em vez de a ade- } \\
\text { são ao direito interno. }\end{array}$ \\
\hline Direito à propriedade privada & Nenhum caso achado. & $\begin{array}{l}\text { Claramente extorsão de subornos viola o } \\
\text { direito à propriedade privada. }\end{array}$ \\
\hline Direito à educação & $\begin{array}{l}\text { Apenas dois casos, nenhum lidando } \\
\text { diretamente com a corrupção. }\end{array}$ & Corrupção leva à violação de tal princípio. \\
\hline
\end{tabular}

Esses casos, pois, são exemplos de como que os direitos humanos, em âmbito jurisdicional, pode se relacionar com a corrupção; bem como essa temática tem sido tratada. Ademais, o quadro também serve para tornar claro, por meio de exemplos, a conexão entre a corrupção e os direitos humanos, central para compreensão deste artigo.

A corrupção, em qualquer dos seus níveis, trazem altos custos para o desenvolvimento. Abusos em um determinado setor podem desencadear danos colaterais em outras áreas. A corrupção pode se manifestar das formas mais sutis, minando a confiança pública no governo e nos serviços que são prestados por este. ${ }^{71}$

71 TRANPARÊNCIA INTERNACIONAL. The anti-corruption catalyst. realising the MDGs by 2015. Berlim, 2010. Disponível em: $<$ http://issuu.com/transparencyinternational/docs/2010_mdg_ en?e $=2496456 / 2052732>$. Acesso em: 18 set. 2014 .

\subsection{Conectando a corrupção a um direito humano específico}

É importante observar como violações de direitos humanos e atos de corrupção podem estar conectados. Este capítulo apresenta, não de maneira exaustiva, exemplos de como conteúdos de direitos específicos podem ser violados por atos de corrupção já definidos na Convenção. ${ }^{72}$

\section{Educação}

Garantido por vários instrumentos internacionais, incluindo os artigos 13 e 14 do Pacto Internacional sobre os Direitos Econômicos, Sociais e Culturais, que traz ao indivíduo o direito de receber uma

72 INTERNATIONAL COUNCIL ON HUMAN RIGHTS POLICY. Corruption and Human Rights: making the connection, Suíça, 2009. Disponível em: <http://www.ichrp.org/files/ reports/40/131_web.pdf>. Acesso em: 12 set. 2014. 
educação, obrigando o Estado a trazer vários tipos de ensino, sendo, na maioria dos países, um dos maiores componentes do setor público, consumindo de $20 \%$ a $30 \%$ do orçamento total. Isso cria oportunidades e incentivos. $\mathrm{O}$ fato de a educação ter um papel único traz consequências que vão além das perdas de fundos públicos quando violada por direitos humanos.

Uma pesquisa realizada em 50 países revela que há uma clara correlação entre o aumento da corrupção e a redução da qualidade e quantidade de em um país. Além disso uma pesquisa feita pela Transparência Internacional em 42 países demonstra o aumento do pagamento de suborno ligado a baixas taxas de alfabetização entre os 15 e 24 anos de idade. ${ }^{74}$

Outra pesquisa realizada no Quênia pelo Center for Governance and Development revelou que o governo queniano perdeu U\$ 475 bilhões com corrupção, negligências e desperdícios. Só Ministério da Educação desperdiçou U $\$ 33,9$ bilhões. A maior parte dessa perda vem de empréstimos de estudantes não amortizados e bolsas institucionais não cobradas, ou seja, fundos desembolsados mas sem nenhuma conta para mostrar a sua utilização. Dessa forma, o relatório presumiu que muitos dos desvios eram para ganho pessoal.

Sendo assim, crianças expostas a corrupção na escola traz a dificuldade em criar uma cultura de transparência a integridade. Os efeitos da corrupção nesse setor são sofridos a curto e longo prazo, perpassando gerações, deixando marcas especialmente profundas e perniciosas.

\section{Saúde}

O direito à saúde traz para o Estado o dever de garantir, em qualquer circunstancia e independente de recursos disponíveis, o acesso aos cuidados da saúde materna e infantil, incluindo o planejamento familiar,

73 TERRACINO, Julio Bacio. Hard law connections between corruption and Human Rights. Genebra, 2010. Disponível em: <http://www. ichrp.org/files/papers/130/131_-_Julio_Bacio_Terracino_-_2007. pdf $>$. Acesso em: 18 set. 2014.

74 TRANPARENCIA INTERNACIONAL. The anti-corruption catalyst: Realising the MDGs by 2015. Berlim, 2010. Disponível em: $<$ http://issuu.com/transparencyinternational/docs/2010_mdg_ en?e $=2496456 / 2052732>$. Acesso em: 18 set. 2014 .

75 GATHII, James Thuo. Defining the relationship between Human Rights and corruption. Pensilvânia, 2013. Disponível em: <http://ssrn. com/abstract $=1342649>$. Acesso em 15 set. 2014.

76 INTERNATIONAL COUNCIL ON HUMAN RIGHTS POLICY. Corruption and Human Rights: making the connection, Suíça, 2009. Disponível em: <http://www.ichrp.org/files/ reports/40/131_web.pdf $>$. Acesso em: 12 set. 2014. imunização contra as principais doenças infecciosas, o tratamento apropriado de doenças e lesões comuns, medicamentos essenciais, abastecimento adequado de água potável e saneamento básico, e estar livre de graves ameaças à saúde ambiental. Nesse setor a corrupção pode ocorrer em três níveis, incluindo: gestão de recursos financeiros, gestão de suprimentos médicos e ainda o profissional de saúde e o paciente. Desse modo, a corrupção afeta a disponibilidade de financiamento do governo para o setor e também reduz a qualidade dos medicamentos e serviços prestados.

As Auditorias de Execução na Libéria relatam graves irregularidades cometidas por funcionários do Ministério da Saúde e Bem-estar Social, sendo identificada uma diferença de aproximadamente U\$ 4 milhões de fundos não contabilizados. Mesmo que bem planejados os programas de saúde, práticas de suborno e outros atos de corrupção comprometem esses programas nacionais. A má gestão de medicamentos levando a suas alterações e desclassificações resulta de 200.000 a 300.000 mortes anualmente na China. Os resultados, com base em dados de 64 países, sugerem que um aumento na corrupção está associada a um aumento da mortalidade materna, independentemente de quão rico um país é ou o quanto ela investe em saúde. $^{78}$

Desvios de bens, recursos públicos, serviços para o uso provado contribuem significativamente para a deterioração da infraestrutura, que afeta a saúde e segurança do público, em especial de pessoas mais pobres. A corrupção generalizada por desvios de recursos públicos para o uso privado afeta negativamente novos investimentos e o crescimento econômico, implicando na desestimulação de novos investidores em países com problemas de corrupção. ${ }^{79}$

Liberdade de Opinião, Expressão e Informação

$\mathrm{O}$ direito à liberdade de opinião, expressão e informação precisa ser protegido não só das interferências públicas, mas também de interferências

77 TERRACINO, Julio Bacio. Hard law connections between corruption and Human Rights. Genebra, 2010. Disponível em: <http://www. ichrp.org/files/papers/130/131_-_Julio_Bacio_Terracino_-_2007. pdf $>$. Acesso em: 18 set. 2014.

78 TRANPARÊNCIA INTERNACIONAL. The anti-corruption catalyst. realising the MDGs by 2015. Berlim, 2010. Disponível em: $<$ http://issuu.com/transparencyinternational/docs/2010_mdg_ en?e=2496456/2052732> . Acesso em: 18 set. 2014.

79 GATHII, James Thuo. Defining the relationship between Human Rights and corruption. Pensilvânia, 2013. Disponível em: <http://ssrn. com/abstract=1342649>. Acesso em 15 set. 2014. 
privadas. A forte ligação entre esses direitos e a corrupção se deve a sua forte importância no combate à corrupção, particularmente no direito à solicitação de informação. A liberdade de divulgar informações e solicitar informação sobre os casos de corrupção diminui os secretismos da prática e ajuda a identificar as causas e consequências da corrupção, além de permitir a concepção de políticas adequadas para combater a corrupção. Como consequência, aqueles que se beneficiam da corrupção precisam suprir esse direito o máximo que puderem. Isso cria situações em que os de casos de corrupção lidam com a violação do direito a liberdade de opinião, expressão e informação. ${ }^{80}$

O Pacto de Direitos Civis e Políticos, em seu artigo 19 garante o direito à liberdade de expressão incluindo a liberdade de ter opiniões sem interferência e de procurar, receber e transmitir informações e ideias por quaisquer meios. Direito este que deve ser protegido contra ingerências públicas e do setor privado. Certamente este direito sofre algumas limitações ou restrições que devem ser interpretadas de maneira restritiva ${ }^{81}$.

Informações sobre o controle das autoridades públicas e o acesso a elas por parte do público são recursos valiosos promovendo transparência a e o accountability por parte das autoridades públicas. Dessa maneira, o cidadão tem acesso a informações sobre como o governo e o setor privado tomam decisões que lhe dizem respeito. Estratégias efetivas para o combate à corrupção dependem da capacidade de expor a corrupção em primeiro lugar. Liberdade de expressão é um requisito importante para incentivar a "cultura política que incentiva, estimula e reforça a exposição e punição" da corrupção, conduzindo a exposição das causas e consequências da corrupção. ${ }^{82}$

80 TERRACINO, Julio Bacio. Hard law connections between corruption and Human Rights. Genebra, 2010. Disponível em: <http://www. ichrp.org/files/papers/130/131_-_Julio_Bacio_Terracino_-_2007. pdf $>$. Acesso em: 18 set. 2014.

81 INTERNATIONAL COUNCIL ON HUMAN RIGHTS POLICY. Corruption and Human Rights: making the connection, Suíça, 2009. Disponível em: <http://www.ichrp.org/files/ reports/40/131_web.pdf>. Acesso em: 12 set. 2014.

82 GATHII, James Thuo. Defining the relationship between Human

\section{Conclusão}

Apesar de já existente reconhecimento de que a corrupção afeta negativamente os direitos humanos e que os movimentos de promoção destes podem estimular o combate à corrupção, estes institutos ainda têm caminhado de maneira paralela. Melhorias significativas na promoção dos direitos humanos demandam que ambos os institutos percorram juntos de maneira interdependente. Isso enseja um papel mais amplo dos Estados e também empresas em combater a corrupção.

Um importante resultado a ser levado em consideração é conceber a agenda de combate à corrupção como uma forma de fomentar a proteção dos direitos humanos. Deve-se levar em conta que as agendas de combate à corrupção consideram termos econômicos e sociais, de maneira que é possível observar que os atos de corrupção levam um Estado ao não cumprimento das suas obrigações de direitos humanos.

Esse trabalho busca explorar a relação entre os direitos humanos e a corrupção, de maneira que essa relação deva ser uma preocupação real nas medidas de combate à corrupção.

Ainda é necessário um progresso além das análises dos impactos negativos da corrupção nos direitos humanos. Constatou-se que, nas avaliações das leis internacionais de proteção dos direitos humanos, estas carecem de uma identificação de como promover esforços destinados a combater a corrupção. Além disso, foram exploradas neste estudo as medidas éticas empresarias discutidas principalmente pelo Pacto Global das Nações Unidas e pelos Princípios Orientadores sobre Empresas e Direitos Humanos que procuram promover a proteção dos direitos humanos.

Rights and corruption. Pensilvânia, 2013. Disponível em: <http://ssrn. com/abstract $=1342649>$. Acesso em 15 set. 2014. 


\section{Referências}

BARBOSA, Carlos Henrique N. A Cooperação internacional à luz da UNCAC: impactos no Brasil. 2014. Monografia (Graduação) - Faculdade de Direito - FD da Universidade de Brasília- UnB, Brasília, 2014.

BARR, Joshua V.; FINKE, Jorge; PINILLA, Edgar Michael. A legal perspective on the use of models in the fight against corruption. Carolina do Sul, 2012. Disponível em: $<$ http://scholarcommons.sc.edu/scjilb/vol8/iss2/5>. Acesso em: 02 set. 2014.

BERENBEIM, Ronald. Linking Human Rights and to anti-corruption: how corruption connects with violations of Human Rights. Vital Speeches of the day, Nova York, v. 77, n. 2, p. 75-76, fev. 2011.

BISHARA, N; HESS, D. Human Rights and Corporation's Duty to Combat Corruption, Michigan. 2013. Disponível em: <http://ssrn.com/abstract $=2388395>$. Acesso em: 02 set. 2014.

BLITT, Robert C. Beyong Ruggie's guiding principles on busniss and Human Rights: charting an embracive approach to Coporate Human Rights Compliance. Texas International Law Journal, Texas, v. 48, n. 158, p. 33- 62, mar. 2013.

BRASIL. Decreto lei 3.678, de 30 de novembro de 2000. Promulga a convenção sobre o combate da corrupção de funcionários públicos estrangeiros em transações comerciais internacionais, concluída em Paris, em 17 de dezembro de 1997. Brasília, 2000. Disponível em: <http://www.planalto.gov.br/ccivil_03/decreto/ D3678.htm>. Acesso em: 31 ago. 2014.

BRASIL. Ministério da Justiça. Guia para o uso do Sistema Interamericano de Direitos Humanos naproteção dos denunciantes de atos de corrupção. Brasília, 2014. Disponível em: $<$ http://www.justica.gov.br/sua-protecao/lavagem-dedinheiro/institucional-2/publicacoes/arquivos/guiapara-uso-do-sidh-na-protecao-de-denunciantes-deatos-de-corrupcao.pdf $>$. Acesso em: 01 out. 2014.

CLOOTS, Ann Sofie; RYNGAET, Cedric; WOUNTERS, Jan. The Fight Against Corruption in InternationalLaw. Bélgica, 2012.Disponível em: <https:// ghum.kuleuven.be/ggs/publications/working_papers/ new_series/wp91-100/wp94-jwouters-cryngaertacloots.pdf> Acesso em: 31 ago. 2014.
DARROUGHM, Masako N. The FCPA and the OCDE Convention: some lessons from U.S. experience. Nova York, 2010. Disponível em: <http://www.jstor.org/ stable/40605340>. Acesso em 02 set. 2014.

FARRALES, M. J. What is corruption? A bistory of corruption studies and the great definitions debate. Carlifórnia, 2005. Disponível em: <http://papers.ssrn.com/sol3/ papers.cfm?abstract_id=1739962>. Acesso em: 02 set. 2014.

GATHII, James Thuo. Defining the relationship between Human Rights and corruption. Pensilvânia, 2013. Disponível em: <http://ssrn.com/abstract $=1342649>$. Acesso em 15 set. 2014.

GEBEYE, Berihun Adugna. Corruption and Human Rights: exploring the relationship. Etiópia, 2012. Disponível em: <http://www.du.edu/korbel/hrhw/ workingpapers/2012/70-gebeye-2012.pdf $>$ Acesso em: 14 set. 2014.

GOULD, D. J. Administrative corruption Incidence, causes and remedial strategies. In: FARAZMAND, Ali. Hand book of comparative development and public administration. Nova York: Taylor \& Francis e-Library, 2005. p. 872-886.

HECHLER, H. et. al. Can UNCAC address grand corruption? A political economy analysis of the UN Convention against Corruption and its implementation in three countries. Berga, 2011. Disponível em: <http:// www.u4.no/publications/can-uncac-address-grandcorruption/>. Acesso em: 31 ago. 2014.

INTERNATIONAL COUNCIL ON HUMAN RIGHTS POLICY. Corruption and Human Rights: making the connection. Suíça. 2009. Disponível em: <http://www.ichrp.org/files/reports/40/131_web. pdf>. Acesso em: 12 set. 2014.

JOHNSTON, Michael. The political consequences of corruption: a reassement. ph.D. Nova York, 1986. Disponível em: <http://www.jstor.org/stable/421694>. Acesso em: 30 ago. 2014.

KOECHLIN, Lucy; CARMONA, Magdalena Sepúlveda. In: ROTBERG, Robert I. Corruption, global security and world order. Washington D.C.: Brookings Institution Press, 2009. p. 310-340. 
MICHAEL, Bryane; HAJREDINI, Habit. Topics in anti-corruption law: what does Kosovo teach us about using human rights law to prosecute corruption offences? Estocolmo, 2010. Disponível em: <http:// works.bepress.com/bryane_michael/52>. Acesso em: 14 set. 2014.

ORGANIZAÇÃO DAS NAÇÕES UNIDAS. Convenção das Nações Unidas Contra a Corrupção (UNCAC). Mérida: 2005.

ORGANIZAÇÃO DAS NAÇÕES UNIDAS. Declaração Universal dos Direitos Humanos, 10 dez, 1948.

ORGANIZAÇÃO DAS NAÇÕES UNIDAS. United Nations Global Compact. 2014.

UNITED NATIONS. A/RES/51/59: 82nd plenary meeting, 12 December 1996 Viena. 1997. Disponível em: $\quad<$ http://www.un.org/documents/ga/res/51/ a51r059.htm>. Acesso em: 31 ago. 2014.

SARFATY, Galit A. Human Rights meet securities regulations, Columbia. 2013. Disponível em: <http:// ssrn.com/abstract=2390192> Acesso em: 02 set. 2014.

SNIDER, Thomas R; KIDANE, Won. Combating corruption through international law in Africa: a comparative analysis. Cornell Intenational Law, Seatle, v. 40, n. 691, p. 691-748, 2007.

SPALDING, Andrew Brady. Corruption, corporations, and the New Human Right. Washington, 2012. Disponível em: <http://ssrn.com/abstract $=2232670>$ Acesso em: 31 ago. 2014.
TERRACINO, Julio Bacio. Hard law connections between corruption and Human Rights. Genebra, 2010. Disponível em: <http://www.ichrp.org/files/papers/130/131_Julio_Bacio_Terracino_-_2007.pdf>. Acesso em: 18 set. 2014.

TRANPARÊNCIA INTERNACIONAL. The Anti-corruption catalyst: Realising the MDGs by 2015. Berlim, 2010. Disponível em: <http://issuu. com/transparencyinternational/docs/2010_mdg_ en?e $=2496456 / 2052732>$. Acesso em: 18 set. 2014.

UNDERKUFF, Laura S. Defining corruption. In: ROTBERG, Robert I. Corruption, global security and world order. Washington D.C: Brookings Institution Press, 2009. p. 27-46.

UNITED NATIONS GLOBAL COMPACT \& TRANSPARENCY INTERNATIONAL. Reporting Guidance on the $10^{\text {th }}$ principle against corruption. 2009. Disponível em: <https://www.unglobalcompact. org/docs/issues_doc/Anti-Corruption/UNGC_ AntiCorruptionReporting.pdf $>$ Acesso em: 02 set. 2014.

UNITED STATES. Department of Justice and Enforcement Division of the U.S. Securities and Exchange Commission. A resource guide to the U.S. foreing corrupt practices act. Washington. 2012. Disponível em: <http://www.justice.gov/criminal/fraud/fcpa/guide. pdf> Acesso em: 31 ago. 2014.

UNITED STATES. Department of Justice's. Foreign Corrupt Practices Act (FCPA). Washington, 1977. Disponível em: $<$ http://www.justice.gov/criminal/ fraud/fcpa/>. Acesso em: 31 ago. 2014. 
Para publicar na Revista de Direito Internacional, acesse o endereço eletrônico www.rdi.uniceub.br ou www.brazilianjournal.org.

Observe as normas de publicação, para facilitar e agilizar o trabalho de edição. 